The thickness of the distinct white layers is $0 \cdot 3-6 \mathrm{~mm}$. It is interesting to note that the white zones of sediment form no seasonal repeat pattern. The following table shows the result of analyses of the dry substance of two white layers (Nos. 1 and 2) and of some dark material (No. 3) ; these were made two years after taking the profile.

No.

Calcium carbonate (per cent)

Insoluble in hydrochloric acid ( $\ddot{p e r}$ cent)

$\begin{array}{rr}\mathbf{1} & \mathbf{2} \\ \mathbf{3 8} & \mathbf{5 2} \\ 7 & 81 \\ 7 & 3\end{array}$

53-58

$53-58$

38

The identity of colour and chemical composition of the white layers with the material causing the turbidity is striking. We therefore assume that each white layer of the Dead Sea bed is caused by an outbreak of turbidity, and that similar outbreaks occurred earlier and are distinctly recorded on the profile. The dark layers, containing much more silicates, are formed by the mineral materials brought annually into the Dead Sea during the normal periods between outbreaks of turbidity. Hence, an exceptional opportunity is thereby offered to investigate the history of the Dead Sea chronologically, and to detect the time of similar 'blanchings' in history by fixing the thickness of the annual dark sedimentation which settles on the 'white lawn' that has formed during the last outbreak.

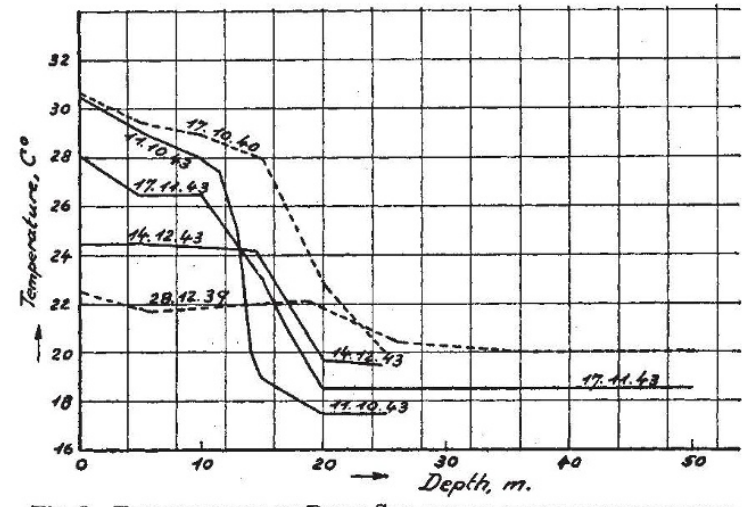

Fig. 2. TEMPERATURE OF DEAD SEA WATER AT DIFFERENT DEPTHS AND TIMES.

Another phenomenon connected with the spontaneous occurrence of turbidity is the change in temperature which took place in the Dead Sea water. It has been assumed that the white colour of the surface water must cause a rise in reflexion of the sun's rays. The assumption was confirmed by measurements of temperature at different depths, which are represented in Fig. 2. We find a difference of as much as $8^{\circ} \mathrm{C}$. in October 1943 as compared with October 1940 , at the depth of $15 \mathrm{~m}$. below the surface. It is noteworthy that the temperature of deeper strata rose again when the turbidity slowly disappeared. This occurred in spite of the fact that the temperature nearer the surface was then lower owing to the progressing winter season. It is therefore most probable that the lower temperature in 1943 was not caused by fluctuation of atmospheric temperature but by the stronger reflexion of the sun's rays.

It may also be assumed that the lower temperature has caused a corresponding reduction of evaporation, but measurements of the sea-level gave no clear picture, because the quantity of rainfall during the preceding winter season was exceptionally large and evaporation during the first month of 1943 was low.
It may, however, be possible to find later on the correlation between the rise of sea-level and the 'blanching' of the Dead Sea and thereby to determine the sea-levels which existed in the past.

We have, of course, tried many explanations for the phenomenon described, but none of them is as yet well enough founded to be of sufficient general interest. Owing to war time conditions, it was unfortunately not possible to make more exhaustive observations and measurements, but it is hoped to clarify some time later the various questions by systematic borings of the Dead Sea bed, and by a careful study of the ancient literature on Palestine and the Dead Sea. We hope that the results will not only be important from geological or even technical aspects, in affording an exact knowledge of sealevels at different times, but also for students of history and of the Bible, since there is a close link between the Dead Sea and the development of religion.

We wish to extend our thanks to the managing director of the Palestine Potash Ltd., Mr. M. Novomejsky, and to those of the Company's staff, who were helpful with suggestions and measurements, especially to Messrs. Campbell, Cahaner, Shirisly and Schnerb.

'Galen, "De Simplicium Medicamentorum Facultatibus", IV, 20; editio Kühn, XI, 690 .

"Ritter, C., "Die Erdkunde von Asien", 764 V/II, par. 9 (Berlin,

${ }^{3}$ Elazari-Volcani, B., Nature, 152, 274 (1943).

\section{INDIAN UNIVERSITY ARCHITECTURE}

$T N$ a paper read before the Indian Institute of Architects early this year, Nawab Zain Yar Jung Bahadur, chief architect, Hyderabad State, dealt with the design of a residential university, as exem. plified in the new Osmania University in Hyderabad. This has been planned on the American campus principle on a site of 1,600 acres, giving ample space for future expansion and the inclusion of well laid-out grounds of impressive dimensions. The author had previously made a fairly thorough study of university architecture both in Europe and the United States, in which connexion he expressed pleasure at the evidence of a master plan in the design of the English universities of Birmingham and Nottingham, but regrets that it is less evident in the case of Edinburgh and Leeds and in most of the Indian universities.

The Osmania University is located in somewhat hilly and picturesque country at Adigmet, a village between Hyderabad and Secunderabad to the northeast of the city, nearly $200 \mathrm{ft}$. above the level of the city, of which it commands beautiful views. Among the ridges on which the University is being built the highest has been set apart for the senate hall, which is to be a monumental building and the keystone of the whole project. On one side of it is the arts college, already completed, and on the other the library and law college will be built. These will form the central group of the main axis. There are two ridges stretching from the senate hall hill: on the left ridge all the science colleges are or will be located, three of which-physics, chemistry, and biology-are already under construction. The ridge to the right has been reserved for the museum and the training college, the training school, the school of arts and the art gallery. The hostels and dining halls are situated in the loop behind the science 
colleges, and the residential area for the teaching staff is beyond the hostels.

In addition to these, sites have been selected for the medical college and hospital, the colleges of agriculture and forestry, the college for women, a students union, a faculty club, a market, a post and telegraph office, botanical garden, stadium, gymnasium, swimming pool, and a colony for subordinates and servants. It is interesting to note, in regard to acoustics, that only large lecture theatres have been given acoustical treatment, and only those rooms where quiet is absolutely essential, owing to the heavy cost of acoustic materials.

One of the main causes of disease in India is said to be the impurity of drinking water; and the question of having separate drinking water for caste Hindus is also a problem for schools and colleges which cannot be ignored. To meet fully the special needs in this respect and minimize risk of infectious disease, modern drinking fountains are being installed throughout.

In regard to style, the author said that in other important countries of the world the science of architecture has made rapid progress, but in India he thinks they are sadly behind the times; and in spite of the money that has been and is being spent on educational institutions, he has seen nothing yet of real architectural value. "In fact some of the buildings are so poorly designed and so badly constructed that they are a blot on the landscape and invoke in the heart an unholy desire to pray for an earthquake or fire." The reigning Nizam, who has taken a keen interest in the new University, expressed the wish that, while possessing all modern facilities, it should have no Western elements in its architecture. Speaking of the arts college at the time of his Jubilee, His Exalted Highness said that "the architecture of this building represents a blending of the Hindu and Muslim styles, and the art and culture of both these races are reflected in the pillars and traceries and carvings on the doors and walls. Thus the building symbolises the close contacts and friendly relations subsisting for centuries between the various classes of my subjects. ... The Osmania University should not only be a repository of Hyderabad's best traditions, a model of its high culture; it should also aim at broadmindedness and mutual toleration and unity among the students, for in that ideal lies the well-being and the prosperity of this State".

The author has accordingly embodied the Hindu and Muslim cultural elements of all periods in the State, such as the Buddhist, Jain, Brahmanic, Bahmani, Kutub Shahi and Moghal. These have all been blended to form a composite whole, signifying the evolution of a new style which should distinguish His Exalted Highness's reign from all the other rulers in the history of the Asafjahi dynasty.

The arts college which, at the beginning of this year, was the only completed building in the scheme, covers an area of $250,000 \mathrm{sq}$. ft. and is designed to accommodate two thousand students. It is a twostoried structure, with basement, built entirely of local granite of pink and grey shades, with the inner walls plastered and the outer surface in ashlar masonry. All the rooms are finished in plain white lime plaster, except the entrance hall, where stucco is used. The dome surmounting the entrance hall is about $50 \mathrm{ft}$. in diameter, resting on corbel slabs. The entrance hall is built in reinforced cement concrete, and is $66 \mathrm{ft}$. from floor to ceiling. The main roof and intermediate floors and staircases are con- structed in reinforced cement concrete. All the floors are paved with polished Shahabad stones from the regions of Tandur and Nawandgi in Hyderabad State, with the exception of the entrance hall, where the floor is red terrazzo. The most difficult and slow part of the work was the process of stone-dressing, as the local granite is of the hardest variety. The stone lintels over the massive columns of the ground floor verandah of the arts college weigh about seven tons each and are $18 \mathrm{in}$. in span. The stones used for the decorative cornices weigh $2 \frac{1}{2}-3 \frac{8}{4}$ tons each. The complete woodwork (including furniture) of the entire buildings is being carried out in the best Rangoon teak. 4,000-5,000 workmen were engaged during the first year or two of the construction work. In addition to local labour many stone-dressers and artisans were imported from southern towns such as Tanjore, Turkapalam and the Conjivaram, to assist directly with the work and also to train the local workers.

The whole scheme is expected to cost a little over two crores, and the author replies to some criticism on the ground that far too much money is being expended on the new University. Before he had seen some of the world's greatest educational centres he was inclined to agree that the cost should be kept low; but examples in other parts of the world convinced him that the University is a nation-building institution in the best sense of the term; the future of the younger generations and of the State itself will obviously depend on the type of University. It is concluded that if the people of India are to be brought physically and mentally to the same level as those of other civilized nations, it is vital that the new University, and others in India, should be built on the principles accepted and the standards fixed in other countries ; and it is quite certain that Hyderabad is a big enough State to think of a big university worthy of itself and of its traditions.

\section{EAST AFRICAN ARCH/EOLOGY}

GIVE distinct types of polished stone axe have been $\mathbf{H}$ recognized in East Africa. Most of the specimens found were pecked and not ground into shape before "being finally polished. No geographical significance can be attached to any of the five types; their distribution will probably be found to be very wide, though for the moment for obvious reasons they have mostly turned up where European settlement involving farming has taken place. A description of the various types, together with a list of some of the localities where they have been found, has been made available in a collection of reprints recently received*. A general sketch map, too, is appended. Finally, a short note on the occurrence of the difterent types outside East Africa concludes the article.

Gorgora, on Lake Tana, was a former Italian military station. The rock-shelter is situated some $150 \mathrm{ft}$. up in the side of a conical hill of volcanic rock which rises abruptly from the plain some three miles from the Lake. The shelter is most inaccessible and can only be approached from one direction. It is some $15 \mathrm{ft}$. long by $8 \mathrm{ft}$. at the widest. Black soil rich in humus was found from the surface to a depth

* "Notes on the Ground and Polished Stone Axes of East Africa", by Mary D. Leakey ; "Excavations of a Rock-Shelter at Gorgora, Lake Tana, Fthiopia", by Colonel F. Moysey; "The Industries of the Gorgora Rock-Shelter, Lake Tana;, by I. S.'B. Leakey. Reprints of the Journal of the East Africa and Uganda Natural History Society,
17 , Nos. 3 and 4 (77 and 78), 182-203. 